\title{
Variations in atmospheric perturbation potential energy associated with the South China Sea summer monsoon
}

\author{
Yazhou Zhang ${ }^{1}$. Jianping $\mathrm{Li}^{1,2}$ (1) - Qiuyun Wang ${ }^{1}$. Jiaqing Xue ${ }^{3,4}$
}

Received: 23 January 2019 / Accepted: 4 June 2019 / Published online: 22 June 2019

(c) The Author(s) 2019

\begin{abstract}
This study investigates the energy conversion processes and their relation to convection (circulation) during the South China Sea summer monsoon (SCSSM) years from the viewpoint of atmospheric perturbation potential energy (PPE). An atmospheric PPE dipole pattern associated with the SCSSM develops over the western North Pacific (WNP) and southern Maritime Continent (SMC) in the boreal summer, serving as a link between the SCSSM and diabatic heating. Actually, the conversion between the energy variations and the convection over the WNP is distinctly different with that over the SMC. The precipitation leads the PPE over the WNP, while similar situation is reversed over the SMC. During strong SCSSM years, the higher PPE over the WNP, controlled primarily by the latent heat released from condensation related to surplus precipitation, is corresponding to the negative energy conversion $\left(\mathrm{C}_{k}\right)$ over there. This indicates that more PPE is converted to perturbation kinetic energy and further intensifying ascending motion over the WNP. Consequently, the descending movement reduces the PPE and is corresponding to positive $\mathrm{C}_{k}$ over the SMC, suggesting that the less PPE converts into the perturbation kinetic energy and in turn favors the descending movement and deficit precipitation there. The enhanced southwesterly induced by this SCSSM Hadley circulation, superimposed on the mean southwesterly wind, further favors the intensification of the SCSSM, implying that the SCSSM can maintain development through the positive convection-PPE-circulation feedback.
\end{abstract}

Keywords South China Sea summer monsoon - Atmospheric perturbation potential energy (PPE) - Energy conversion · Perturbation kinetic energy $\cdot$ Positive circulation-PPE-convection feedback

\section{Introduction}

Electronic supplementary material The online version of this article (https://doi.org/10.1007/s00382-019-04845-7) contains supplementary material, which is available to authorized users.

Jianping Li

ljp@ouc.edu.cn

1 College of Global Change and Earth System Science (GCESS), Beijing Normal University, Beijing 100875, China

2 Key Laboratory of Physical Oceanography, Institute for Advanced Ocean Studies, Qingdao National Laboratory for Marine Science and Technology, Ocean University of China, Qingdao 266100, China

3 State Key Laboratory of Numerical Modeling for Atmospheric Sciences and Geophysical Fluid Dynamics, Institute of Atmospheric Physics, Chinese Academy of Sciences, Beijing 100029, China

4 College of Earth Science, University of Chinese Academy of Sciences, Beijing 100029, China
The South China Sea (SCS) is part of the tropical Indian-western Pacific warm pool and lies at the center of the Asian-Australian monsoon system, which plays an important role in moisture transport from the North Indian Ocean and Southern Hemisphere to China (Wu et al. 2006). The SCS summer monsoon (SCSSM), as the remarkable year-to-year variability over the SCS region, is closely associated with intense convective activity and changes in atmospheric circulation ( $\mathrm{Li}$ and Zeng 2002; Wang et al. 2009), and exerts a great influence on adjacent regions (Wu et al. 2010; Zhang et al. 2018). Previous studies have demonstrated the intimate connection between the atmospheric circulation related to the SCSSM and external forcing: e.g., sea surface temperature (SST) and the Southern Annular Mode (Xie et al. 2009; He and Wu 2014; He et al. 2016; Liu et al. 2017). However, the formation and maintenance of the atmospheric general circulation related to the SCSSM is essentially controlled by the perturbation kinetic energy 
(PKE) of the climate system, and less attentions are paid into the monsoon study from the viewpoint of the energetics. Thus, exploring precisely the energy variations and their relation to the atmospheric circulation during the SCSSM years are better not only to deepen the understanding of the dynamic processes of the SCSSM system, but to promote the regional energetics development of the monsoon community.

In the atmospheric energy theory, PKE cannot be transformed directly from diabatic heating. Although the atmospheric available potential energy (APE) can serve as the medium that links diabatic heating and PKE (Lorenz 1955), this does not occur at the regional scale because APE is calculated as the global mean. To overcome these limitations, $\mathrm{Li}$ and Gao (2006) extended the APE to the local scale and proposed the concept of atmospheric perturbation potential energy (PPE), which represents the maximum amount of total potential energy that can be converted into PKE at the local scale. A detailed introduction to atmospheric PPE theory is provided in Sect. 2.1 (also see the Supporting Information).

The atmospheric PPE theory has been successfully used to investigate the atmospheric energetics of global climate variability (Gao and Li 2007, 2012, 2013; Wang et al. 2015; Dong et al. 2017; Wang et al. 2018a, b), illustrating its practical value to regional climate research, especially in the study of monsoon systems (Wang et al. 2012; Huyan et al. 2017). Huyan et al. (2017) found that the East Asian summer monsoon is significantly correlated with the PPE anomalies over three key regions: the eastern Indian Ocean $\left(72.5^{\circ}-110^{\circ} \mathrm{E}\right.$, $\left.10^{\circ} \mathrm{S}-10^{\circ} \mathrm{N}\right)$, subtropical central Pacific $\left(175^{\circ} \mathrm{E}-160^{\circ} \mathrm{W}\right.$, $\left.10^{\circ}-20^{\circ} \mathrm{N}\right)$, and mid-latitude East Asian $\left(115^{\circ}-140^{\circ} \mathrm{E}\right.$, $30^{\circ}-40^{\circ} \mathrm{N}$ ) in the boreal summer (June-July-August, JJA), implying that the East Asian summer monsoon is physically linked with the PPE not only over the local monsoon region but also over the remote regions. Wang et al. (2012) investigated the energy budget of the SCSSM activity from the perspective of PPE, but focused on the intraseasonal scale. However, the SCSSM shows a prominent interannual variability, and associated PPE variations remain unclear. In addition, the intimate relationships of the SCSSM with the El Niño-Southern Oscillation (ENSO) and the Indian Ocean dipole (IOD) during JJA are reported in prior studies (e.g., Wang et al. 2009; Zhang et al. 2018). Thus, this study further investigates the atmospheric energy variations and relevant convection (circulation) changes associated with the interannual variability of the SCSSM from the viewpoint of atmospheric PPE, and provides a new perspective to improve our understanding of the interaction between the SCSSM and ENSO/IOD.

The remainder of this paper is organized as follows. Section 2 provides a brief review of the atmospheric PPE theories, datasets and methods used in this work. Our diagnostic results are interpreted in Sect. 3. We first examine the relationship between the SCSSM and atmospheric PPE, before considering the mechanism that links the energy conversion between atmospheric PPE and PKE with corresponding changes in the atmospheric circulation, and further exploring the possible diabatic heat (sink) associated with atmospheric PPE. The potential linking to ENSO and IOD are briefly discussed in Sect. 4. Finally, a summary is presented in Sect. 5.

\section{Theories, datasets and methods}

\subsection{Atmospheric PPE}

Although Margules (1910) was the first to propose the theory of atmospheric energy availability, it was Lorenz (1955) who provided the modern framework for atmospheric energetics, and the concept of APE became widely accepted and applied to the global atmospheric and oceanic energy budget (Oort 1964, 1971; Peixóto and Oort 1974; Oort et al. 1989; Li et al. 2007, 2011; Kim and Kim 2013; Roullet et al. 2014; Pan et al. 2017). As it is based on the global average, the APE cannot be used to diagnose regional atmospheric energetics, although several studies have tried to expand the APE to the local scale by incorporating the energy flux at the boundary of the chosen study region adding the boundary energetics fluxes (Smith 1969; Johnson 1970; Smith et al. 1977; Edmon Jr 1978). Furthermore, the minimum total potential energy is defined as the atmospheric reference state of the APE if the stratification is horizontal and statically stable; however, this ideal reference condition is physically unrealistic.

To overcome these limitations, Gao et al. (2006) reported that the adiabatic redistribution of the atmosphere is under physical constraints, and the concept of atmospheric PPE was proposed by Li and Gao (2006), defined as the difference in atmospheric total potential energy between the actual state and the conditional minimum reference state via any adiabatic redistribution. The PPE equation, in isobaric coordinates, is as follows (detailed derivations can be found in the Supporting Information):

$\mathrm{PPE}=\sum_{i=1}^{\infty} \mathrm{PPE}_{i}=\sum_{i=1}^{\infty} \frac{p_{00}^{(i-1) \kappa} \prod_{j=0}^{i=1}(1+\kappa-j)}{i ! \gamma_{d}(1+\kappa)} \int_{0}^{P_{S}} \frac{T^{i}}{p^{(i-1)(1+\kappa)}}\left(-\frac{\partial \bar{\theta}}{\partial p}\right)^{-i+1} d p$, 
where $i$ is the order of moment term of PPE; $p, p_{00}$, and $P_{S}$ are the pressure, reference pressure (generally $1000 \mathrm{hPa}$ ), and surface pressure, respectively; $\kappa=R / c_{p}$, where $R$ and $c_{p}$ are the gas constant of dry air and the specific heat at a constant pressure, respectively; $\gamma_{d}=g / c_{p}$ indicates the dry adiabatic lapse rate; and $\bar{\theta}$ and $T^{\prime}$ denote the potential temperature at the conditional minimum reference state and the departure of temperature, respectively. Thus, the mathematical expressions of the first and second moment terms of PPE can be written as:

$\mathrm{PPE}_{1}=\frac{1}{\gamma_{d}} \int_{0}^{P_{S}} T^{\prime} d p$

$$
\mathrm{PPE}_{2}=\frac{\kappa p_{00}^{\kappa}}{2 \gamma_{d}} \int_{0}^{P_{S}} \frac{T^{\prime 2}}{p^{1+\kappa}}\left(-\frac{\partial \bar{\theta}}{\partial p}\right)^{-1} d p,
$$

here $\mathrm{PPE}_{1}$ and $\mathrm{PPE}_{2}$ denote the first and second moment terms of PPE, respectively. In contrast to $\mathrm{PPE}_{1}$ and $\mathrm{PPE}_{2}$, the higher-moment terms of PPE are much smaller and can be omitted at the local scale ( $\mathrm{Li}$ and Gao 2006). Thus, atmospheric PPE is calculated in this paper as the sum of $\mathrm{PPE}_{1}$ and $\mathrm{PPE}_{2}$.

\subsection{Datasets}

The daily and monthly mean air temperature, sea level pressure, and vertical velocity derived from the National Centers for Environmental Prediction-National Center for Atmospheric Research (NCEP/NCAR) reanalysis dataset were used to calculate atmospheric PPE and the energy conversion term at each grid, and daily and monthly mean horizontal winds were to obtain the weekly and monthly SCSSM index (Kalnay et al. 1996). To analyze the diabatic heating, the monthly mean horizontal winds, surface sensible heat flux, surface latent heat flux, net shortwave radiation flux, net longwave radiation flux, precipitation rate, specific humidity, and precipitable water content datasets used in this study were also taken from the NCEP/NCAR reanalysis dataset (Kalnay et al. 1996). The study period is 1948-2015, and the horizontal gridded resolution is $2.5^{\circ} \times 2.5^{\circ}$ for the NCEP/ NCAR reanalysis dataset. To demonstrate the robustness of our results, we have used another two datasets available at period $1979-2015$ on a $2.5^{\circ} \times 2.5^{\circ}$ grid: the NCEP Reanalysis-2 (NCEP2) data is provided by the NOAA/OAR/ ESRL Physical Sciences Division (PSD), Boulder, Colorado, from their website (https://www.esrl.noaa.gov/psd/ data/gridded/data.ncep.reanalysis2.html) (Kanamitsu et al. 2002); and another one is from the monthly European Centre for Medium-Range Weather Forecasts (ECMWF) interim reanalysis (ERA-Interim; Dee et al. 2011). The improved Extended Reconstructed SST version 5 (ERSST v5) and the Hadley Centre Sea Ice and SST (HadISST) datasets on a $1^{\circ} \times 1^{\circ}$ grid for the same period were used to examine the relationship between the air-sea temperature difference and surface sensible heat fluxes (Rayner et al. 2003; Huang et al. 2017). We removed the linear trend and the long-term (1948-2015) mean climatology from each dataset before analysis.

Li and Zeng $(2002,2003)$ defined the dynamical normalized seasonality monsoon index in terms of the intensity of the seasonal wind field, and this index can be used to measure the seasonal cycle and interannual variability in global monsoon regions (Li et al. 2010; Liu et al. 2017; Zhang et al. 2018). The index is defined as follows:

$\delta=\frac{\left\|\overline{\mathrm{V}}_{1}-\mathrm{V} m, n\right\|}{\|\bar{V}\|}-2$,

where $\|*\|$ is a norm on the monsoon domain of integration. $\overline{\mathrm{V}}_{1}$ and $\bar{V}$ denote the climatological mean wind vectors in January and the mean of the January and July climatological wind vectors, respectively, and $\mathrm{V} m, n$ indicates the monthly wind vectors in the $m$ th month of the $n$th year. The SCSSM index is defined as an area-average over the SCS monsoon domain $\left(100^{\circ}-125^{\circ} \mathrm{E}, 0^{\circ}-25^{\circ} \mathrm{N}\right)$ in the 925 -hPa wind field during JJA based on the dynamical normalized seasonality. In addition, The Niño-3.4 index calculated from the SST anomalies area-averaged over the equatorial central Pacific $\left(5^{\circ} \mathrm{S}-5^{\circ} \mathrm{N}, 120^{\circ} \mathrm{W}-170^{\circ} \mathrm{W}\right)$ is to denote ENSO. The IOD index is defined as the difference in SST anomalies between the tropical western Indian Ocean $\left(50^{\circ}-70^{\circ} \mathrm{E}, 10^{\circ} \mathrm{S}-10^{\circ} \mathrm{N}\right)$ and the southeastern Indian Ocean $\left(90-110^{\circ} \mathrm{E}, 10^{\circ} \mathrm{S}-0^{\circ}\right)$.

\subsection{Methods}

The correlation and composite analyses are applied into this study. In order to explore the relationships of the SCSSM, the PPE, and precipitation, we calculate the lead-lag correlations between them. The significance of correlations between variables $X$ and $Y$ was tested by a two-tailed Student's $t$ test using the effective number of degrees of freedom $\left(N_{e f f}\right)$, which can be given as following approximation (e.g. Bretherton et al. 1999; Pyper and Peterman. 1998; Li et al. 2013):

$\frac{1}{N_{e f f}} \approx \frac{1}{N}+\frac{2}{N} \sum_{i=1}^{N} \frac{N-i}{N} \rho_{X X}(i) \rho_{Y Y}(i)$,

where $N$ indicates the total size of time series; $\rho_{X X}(i)$ and $\rho_{Y Y}(i)$ represent the autocorrelations of two time series $X$ and $Y$ at time lag $i$, respectively. 


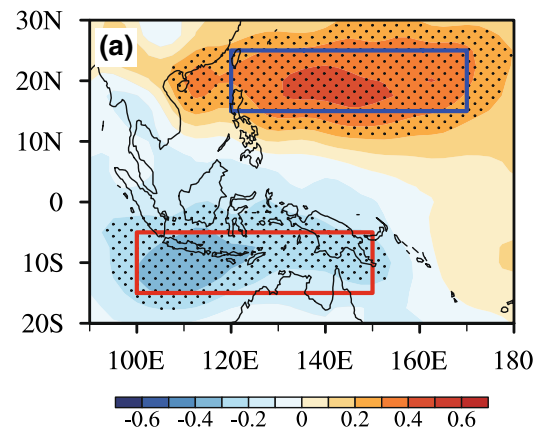

Fig. 1 a Correlations between the SCSSM index and atmospheric PPE anomalies (shading) during JJA; black stipples indicate significance at the $95 \%$ level. The blue and red rectangles in a denote the western North Pacific (WNP; $120^{\circ}-170^{\circ} \mathrm{E}, 15^{\circ}-25^{\circ} \mathrm{N}$ ) and the southern Maritime Continent $\left(\mathrm{SMC} ; 100^{\circ}-150^{\circ} \mathrm{E}, 15^{\circ}-5^{\circ} \mathrm{S}\right)$ regions, respectively. b Standardized time series of the SCSSM index and the

\section{Results}

\subsection{Relationship between the SCSSM and atmospheric PPE}

Figure 1a shows the spatial correlation between the SCSSM and atmospheric PPE over the Indian-western Pacific region. The SCSSM is significantly correlated with PPE over two key regions: the western North Pacific (WNP; $120^{\circ}-170^{\circ} \mathrm{E}$, $15^{\circ}-25^{\circ} \mathrm{N}$ ) and southern Maritime Continent (SMC; $\left.100^{\circ}-150^{\circ} \mathrm{E}, 15^{\circ}-5^{\circ} \mathrm{S}\right)$, locating at the north and south sides
PPE dipole index in JJA for period 1948-2015; $R$ indicates that the correlation coefficient between the two series exceeds the $99 \%$ confidence level. Here, the PPE dipole index is defined as the difference in atmospheric PPE anomalies between the WNP and SMC, as shown in (a)

of the SCS monsoon region and showing a dipole pattern (Fig. 1a). To better demonstrate the characteristics of this dipole pattern, the PPE dipole index is simply defined as the difference in PPE anomalies between the WNP and the SMC, and standard time series of the SCSSM index and PPE dipole index in JJA are shown in Fig. 1b. The high correlation coefficient $(0.69$, beyond $99 \%$ confidence level) indicates the intimate linkage between the SCSSM and the PPE dipole over the WNP and SMC. The similar results can also be produced by using the NCEP2 and ERA-Interim datasets (Fig. 2), illustrating the robustness of those results.
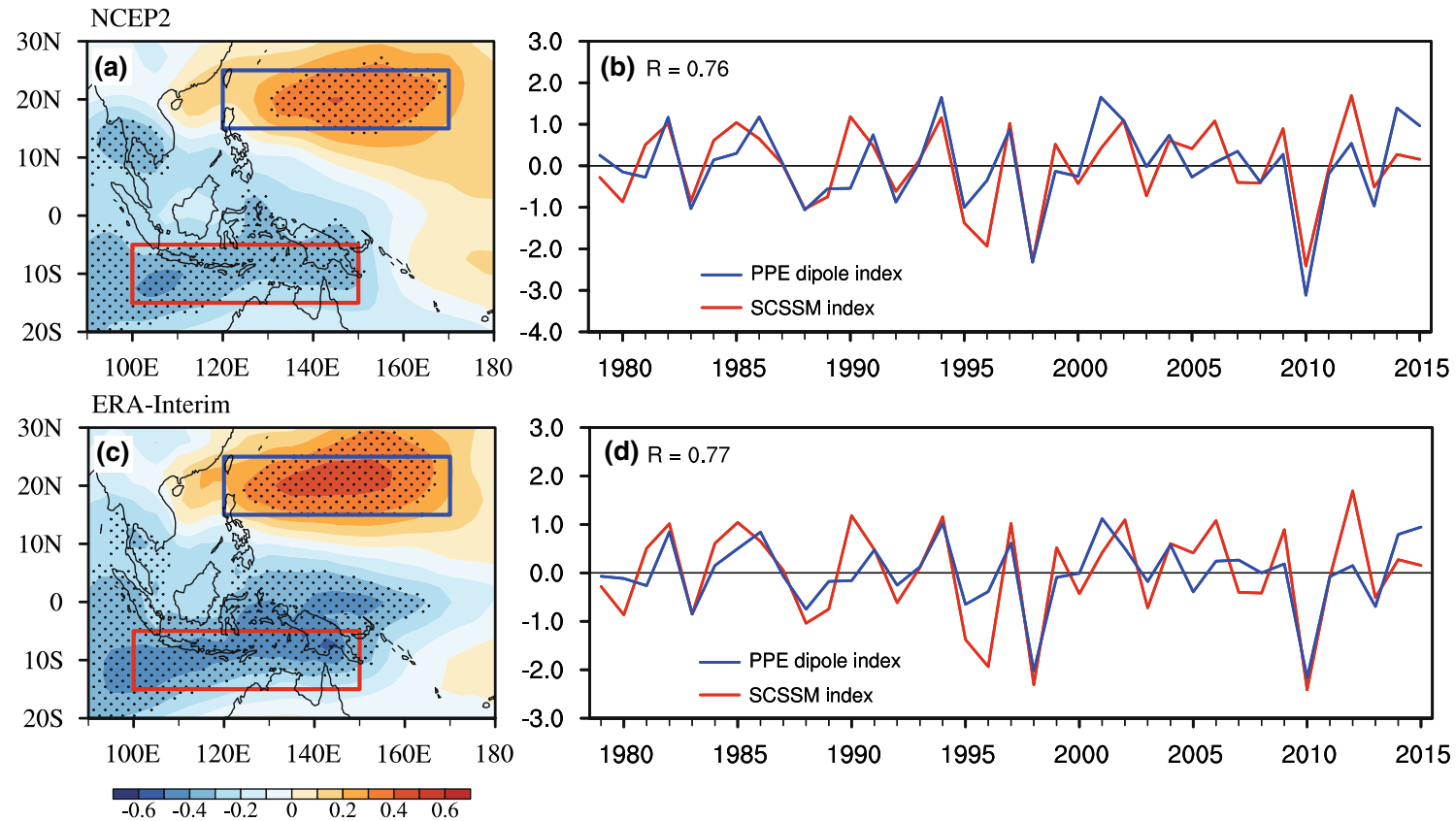

Fig. 2 Same as Fig. 1, but using NCEP2 and ERA-Interim datasets during 1979-2015 


\subsection{Energy conversion and corresponding change in atmospheric circulation}

The energy conversion between the atmospheric PPE and PKE is controlled by the following governing equations:

$\frac{1}{g} \int_{0}^{P_{S}} \frac{\partial P P E}{\partial t} d p=\mathrm{C}_{k}+G+H B F_{P P E}$,

$\frac{1}{g} \int_{0}^{P_{S}} \frac{\partial P K E}{\partial t} d p=-\mathrm{C}_{k}+\mathrm{D}+H B F_{P K E}$

$\mathrm{C}_{k}=\frac{1}{g} \int_{0}^{P_{S}} w \alpha d p$,

where $\mathrm{C}_{k}$ denotes the energy conversion term between atmospheric PPE and PKE, which depends on vertical velocity $(w)$ and atmospheric stability $(\alpha)$. When $\mathrm{C}_{k}<0$, PPE is transformed into PKE; conversely, when $\mathrm{C}_{k}>0, \mathrm{PKE}$ is transformed into PPE. G is the source (sink) term of atmospheric PPE and is closely associated with diabatic heating.
$\mathrm{D}$ and $\mathrm{HBF}$ represent viscous dissipation and horizontal boundary fluxes respectively. The atmospheric diabatic heating $G$ cannot change PKE directly, but first changes PPE according to the governing equations; thus, it is the PPE that plays a bridging role in linking diabatic heating and changes in atmospheric circulation.

To examine the seasonal evolutions of atmospheric PPE and $\mathrm{C}_{k}, 23$ anomalous SCSSM events (14 strong and 9 weak SCSSM events, Table 1) were identified and used to calculate composite anomalies based on the strong SCSSM minus the weak SCSSM. As with the PPE dipole index, the energy conversion index is also defined as the difference in $\mathrm{C}_{k}$ anomalies between the WNP and the SMC. The composites of the PPE dipole index and energy conversion index are shown in Fig. 3a. The reversed relationship between the PPE dipole index and the energy conversion index is first clearly seen, and this is in agreement with the governing equations for atmospheric PPE and PKE (Fig. 3a). The peak period of energy conversion, from June to September, is closely aligned with the mature period of the SCSSM. This means that more PPE (PKE) is converted to PKE (PPE) over the WNP (SMC) as the strong SCSSM develops in JJA, and vice versa. The increased PPE is

Table 1 The classification strong/weak SCSSM events for the period 1948-2015

\begin{tabular}{ll}
\hline Events & Year \\
\hline Strong SCSSM & $1948,1950,1952,1961,1967,1972,1982,1990,1991$, \\
& $1994,2002,2006,2009$, and 2012 \\
Weak SCSSM & $1955,1956,1958,1973,1988,1995,1996,1998$, and 2010 \\
\hline
\end{tabular}

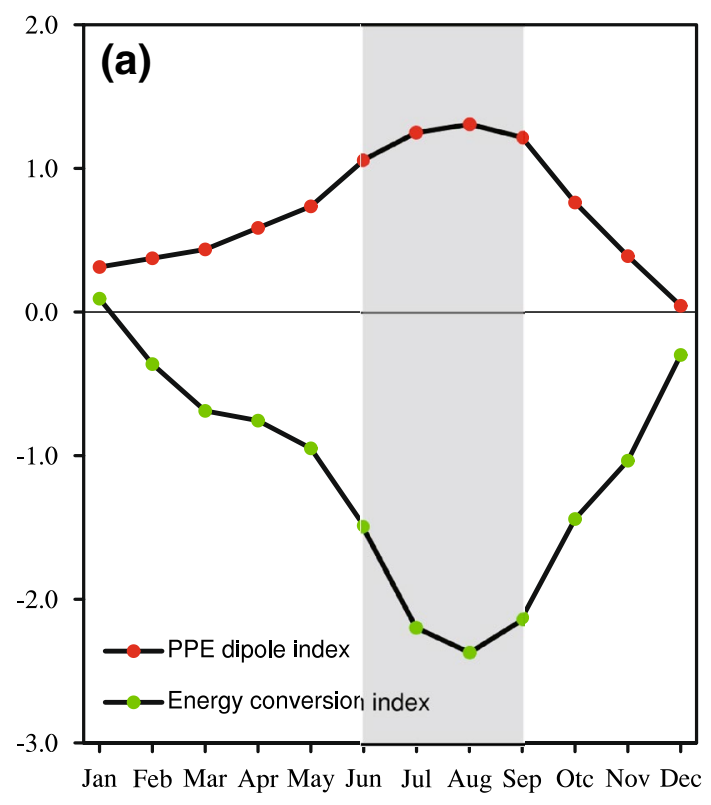

Fig. 3 a Composite of the monthly mean PPE dipole index (red dot) and the energy conversion index (green dot), and the gray shading region presents the period from June to September. b Composite of the atmospheric PPE anomalies (shading, $10^{5} \mathrm{~J} \mathrm{~m}^{-2}$ ) during JJA, and

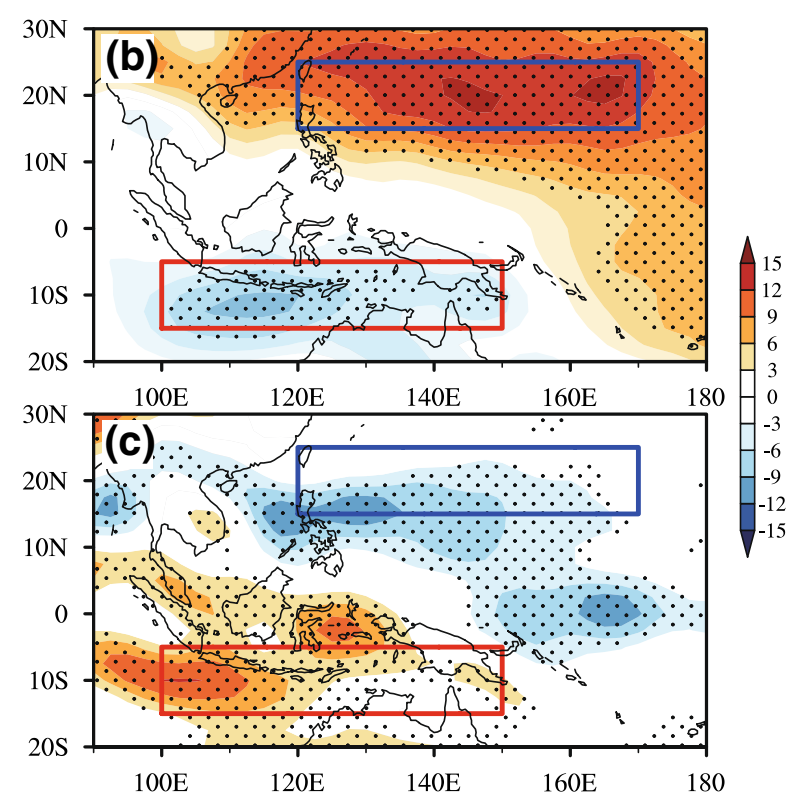

c as $\mathbf{b}$ but for the $\mathrm{C}_{k}$ anomalies (shading, $10 \mathrm{~W} \mathrm{~m}^{-2}$ ). The red (blue) rectangles same as in Fig. 1a. Black stipples in (b) and (c) indicate 95\% confidence level 
accompanied by a reduced $\mathrm{C}_{k}$ over the WNP, and a similar situation occurs in the SMC but with the opposite sign (Fig. 3b, c), which is consistent with results in Fig. 3a. Notably, the atmospheric PPE anomalies over the WNP are stronger than those over the SMC (Fig. 3b), which will be analyzed in Sect. 3.3.

As shown in Eqs. (4) and (5), the atmospheric energy can be converted between PPE and PKE through $\mathrm{C}_{k}$, because $\mathrm{C}_{k}$ is directly linked to the changes in atmospheric circulation described in Eq. (6). When cold air ascends or warm air descends, $\mathrm{C}_{k}$ is positive and energy is converted from PKE to PPE. Conversely, when warm air ascends or cold air descends, $\mathrm{C}_{k}$ is negative and energy is converted from PPE to PKE. Beside of the temporal and spatial distribution of $\mathrm{C}_{k}$ in Fig. 3a, c, the vertical-meridional distribution averaged between $100^{\circ} \mathrm{E}$ and $170^{\circ} \mathrm{E}$ is shown in Fig. 4a. Significant negative $\mathrm{C}_{k}$ anomalies are located at roughly $15^{\circ} \mathrm{N}$, implying the existence of an upward branch of the anomalous SCSSM Hadley circulation (Fig. 4b). Clear positive $\mathrm{C}_{k}$ anomalies are centered at $10^{\circ} \mathrm{S}$ with the wide scales, which is accompanied by anomalous downward motion between $10^{\circ} \mathrm{S}$ and $0^{\circ}$ (Fig. 4b). This suggests the enhancement of an anomalous SCSSM Hadley circulation over the WNP and SMC, which is consistent with the results of Zhang et al. (2018).

Notably, one similar descending branch also exists over the mid-latitude East Asia $\left(30^{\circ}-40^{\circ} \mathrm{N}, 100^{\circ}-150^{\circ} \mathrm{E}\right)$, leading to the weaker intensity of the sinking branch over the SMC in contrast to the ascending branch over the WNP (Fig. 5a). However, the prominent descending branch is located over the SMC because of the larger scale and stronger intensity than that over the mid-latitude East Asia, which can also be verified by the precipitation anomalies (Fig. 5b). The precipitation anomalies over the WNP and SMC are much stronger than that over the mid-latitude East Asia, corresponded with the stronger ascending (descending) motion over the WNP (SMC) and the weaker descending motion over the midlatitude East Asia (Fig. 5).

\subsection{Diabatic heating to atmospheric PPE}

Previous studies have indicated that diabatic heating cannot directly lead to changes in the atmospheric general circulation (Lorenz 1955), and the aforementioned results suggest that atmospheric PPE acts as a link between diabatic heating and the atmospheric general circulation. Thus, determining which diabatic heating terms drive PPE variations over the WNP and SMC is of great interest. Equation (4) demonstrates that PPE variations are controlled by diabatic heating $\mathrm{G}$, energy conversion $\mathrm{C}_{k}$, and the horizontal boundary flux HBF. In contrast to energy conversion $\mathrm{C}_{k}$ and horizontal boundary flux HBF associated with inner atmospheric processes, diabatic heating G plays a dominant role in the PPE variations over the WNP and SMC (Supporting Information Fig. S1). We therefore focus on diabatic heating G, which
Fig. 4 As in Fig. 3b, but for meridional-vertical a $\mathrm{C}_{k}$ anomalies (shading, $100 \mathrm{~W} \mathrm{~m}^{-2}$ ), and b circulation anomalies (vector, $\mathrm{m} \mathrm{s}^{-1}$ ) and vertical pressure velocity anomalies (shading, $-10^{-2} \mathrm{~Pa} \mathrm{~s}^{-1}$ ) averaged over the region $100^{\circ}-170^{\circ} \mathrm{E}$. Black stipples in (a) and shading in (b) indicate significance at the 95\% level

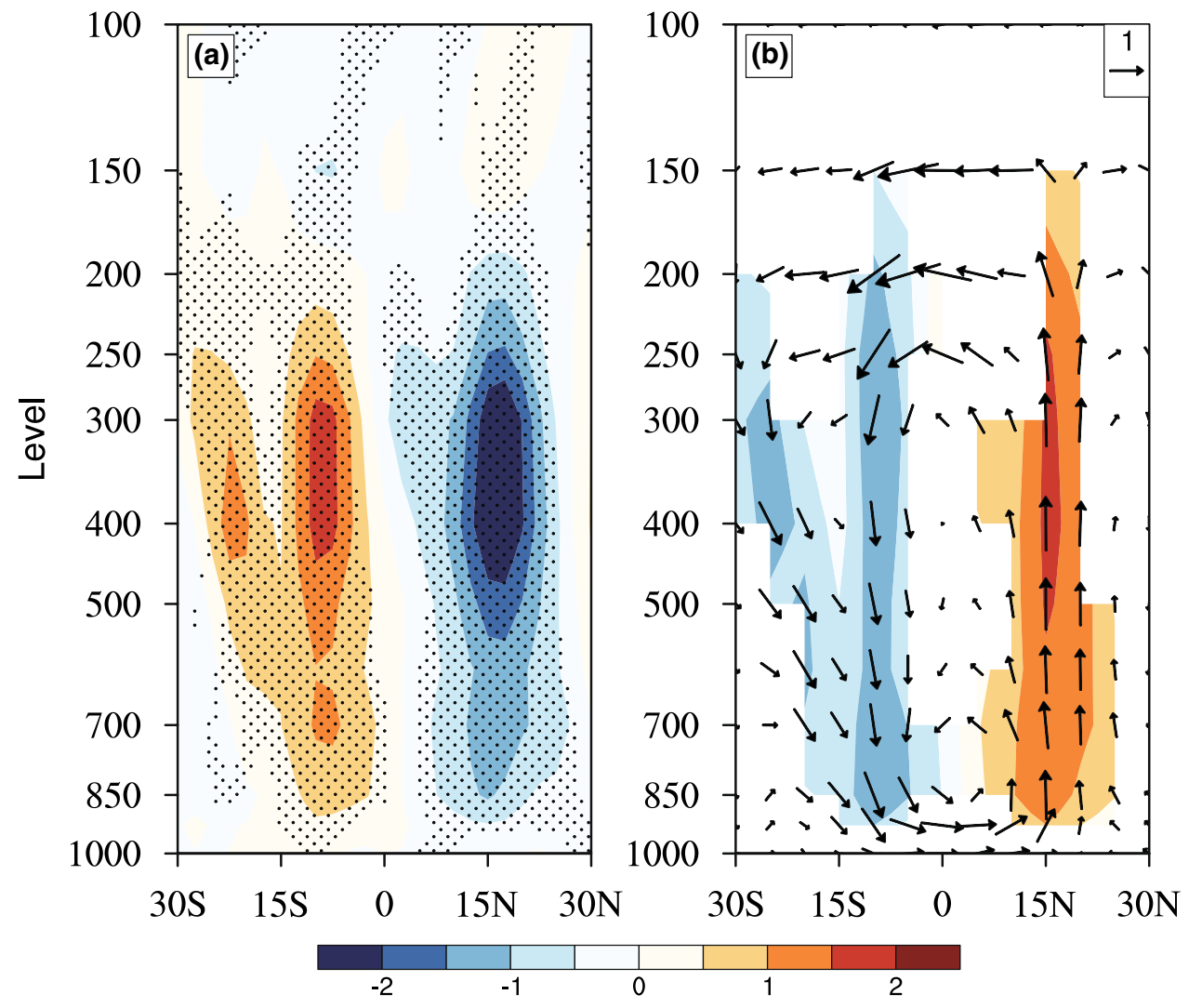


(a)

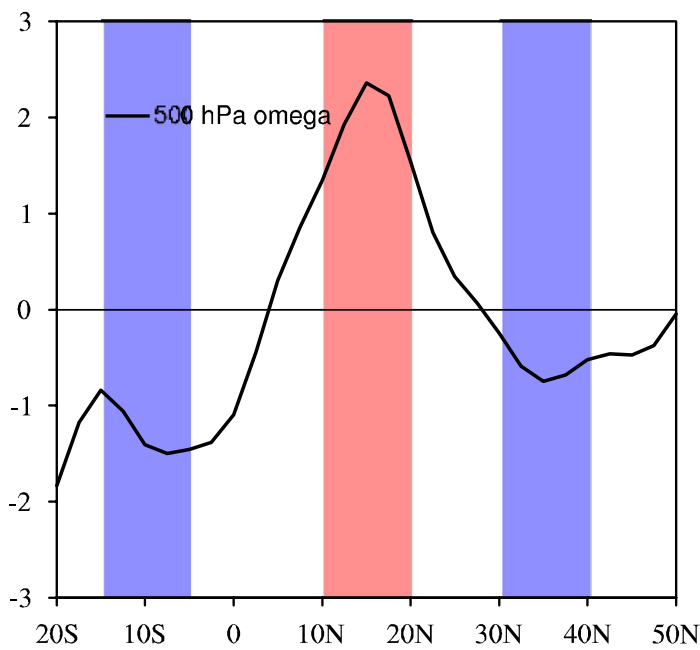

Fig. 5 Composite of the a 500-hPa vertical pressure velocity anomalies (line, $-10^{-2} \mathrm{~Pa} \mathrm{~s}^{-1}$ ) averaged between the $100^{\circ}-150^{\circ} \mathrm{E}$, b precipitation rate anomalies (shading, $\mathrm{kg} \mathrm{m}^{-2} \mathrm{~s}^{-1}$ ). The blue (red) shading regions in (a) are averaged between the $100^{\circ}-150^{\circ} \mathrm{E}$ of the blue (b)

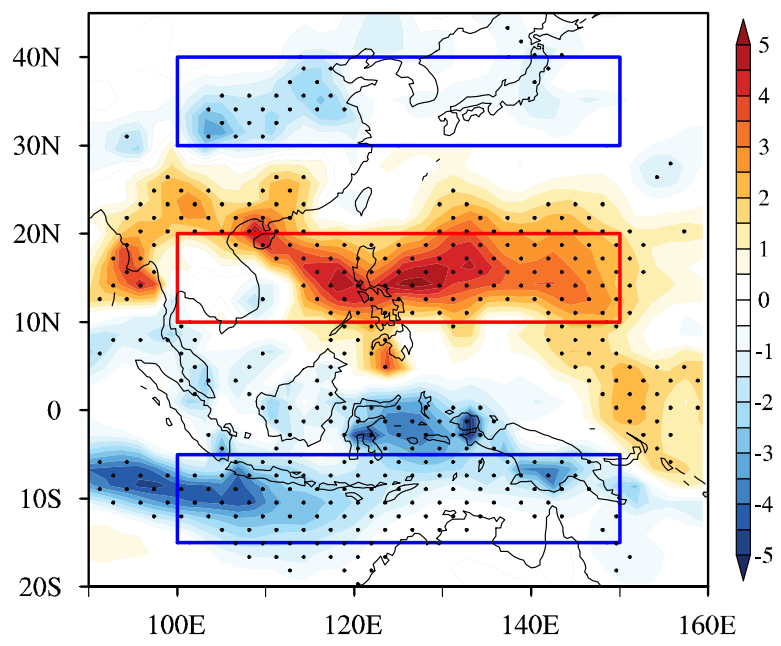

(red) rectangles in $(\mathbf{b})$. The red rectangle in $(\mathbf{b})$ denotes $\left(100^{\circ}-150^{\circ} \mathrm{E}\right.$, $\left.10^{\circ}-20^{\circ} \mathrm{N}\right)$, and blue rectangles indicate $\left(100^{\circ}-150^{\circ} \mathrm{E}, 15^{\circ}-5^{\circ} \mathrm{S}\right)$ and $\left(100^{\circ}-150^{\circ} \mathrm{E}, 30^{\circ}-40^{\circ} \mathrm{N}\right)$ regions, respectively. Black stipples in (b) indicate $95 \%$ confidence level (a) Sensible heat

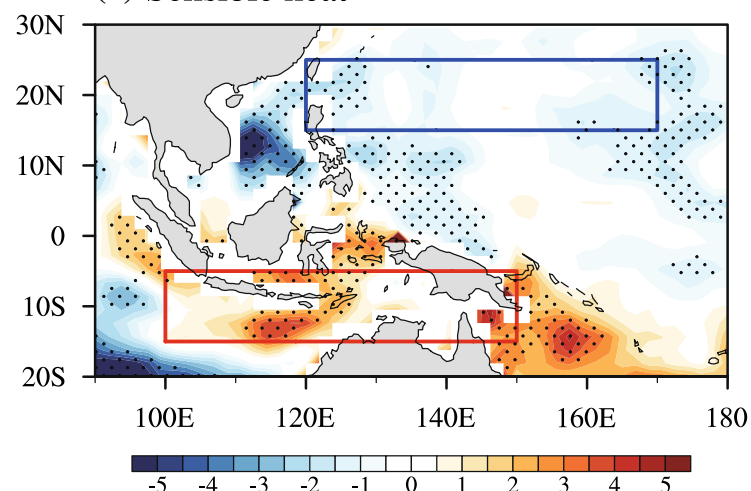

(c) Shortwave + longwvae

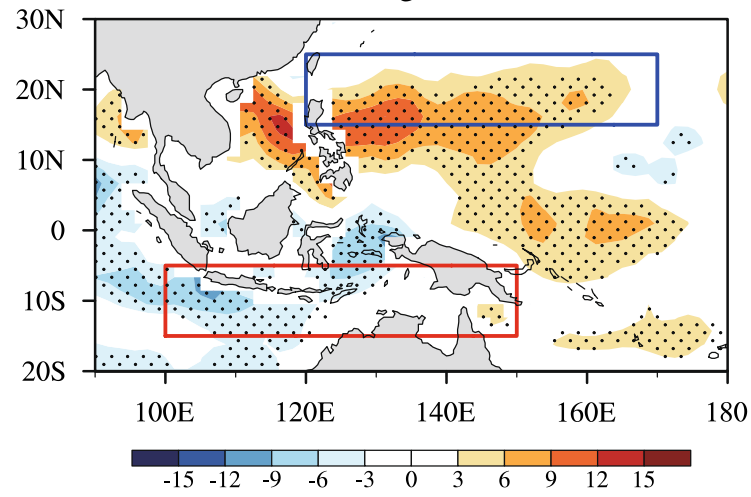

Fig. 6 Composite of the a surface sensible heat flux (shading, $\mathrm{W} \mathrm{m}{ }^{-2}$ ), b surface latent heat flux (shading, $\mathrm{W} \mathrm{m}^{-2}$ ), $\mathbf{c}$ net shortwave and longwave radiation flux (shading, $\mathrm{W} \mathrm{m}^{-2}$ ), $\mathbf{d}$ total flux (the sum

\section{(b) Latent heat}

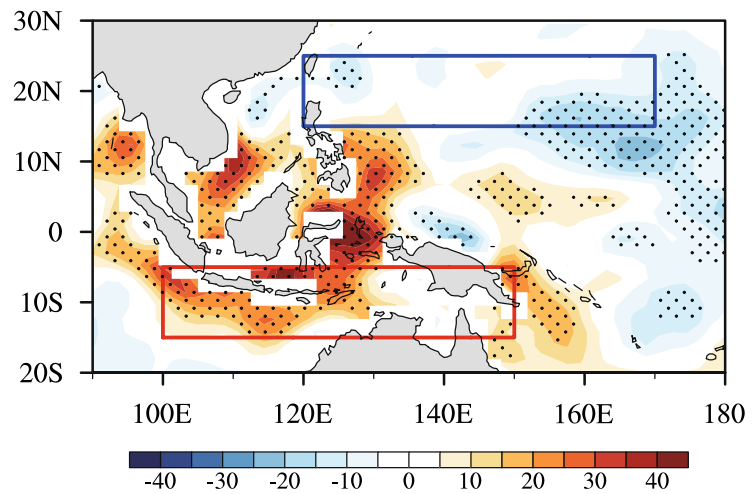

(d) Total flux

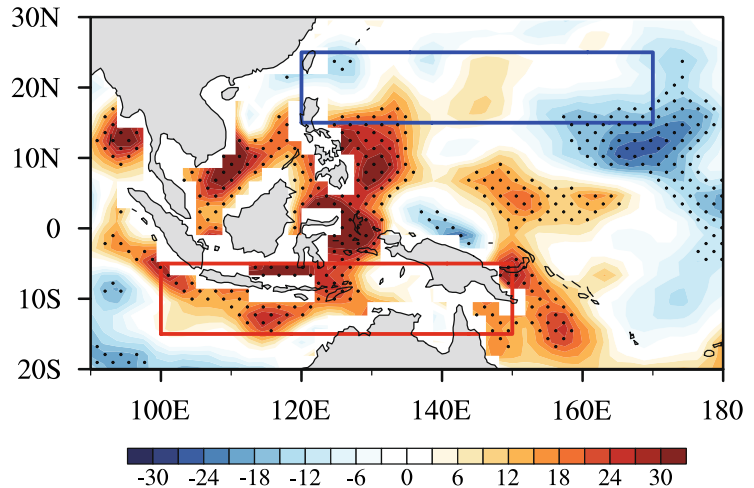

of the $\mathbf{a}, \mathbf{b}$ and $\mathbf{c}$, shading, $\mathrm{W} \mathrm{m}^{-2}$ ) anomalies. The red (blue) rectangles same as in Fig. 1a. Black stipples in (a-d) indicate 95\% confidence level 
comprises mainly the sensible heat, latent heat, shortwave radiation, and longwave radiation fluxes.

Figure 6 shows composites of the surface sensible heat flux, surface latent heat flux, the sum of net shortwave and longwave radiation fluxes, and total surface heat fluxes averaged over the WNP and SMC in JJA. Here, the surface heat fluxes denote the sum of the net longwave radiation, net shortwave radiation, sensible heat, and latent heat fluxes at the surface boundary. The dipole pattern of the surface sensible heat flux anomalies is similar to the PPE anomalies but with opposite sign over the WNP and SMC (Fig. 6a), which is strongly consistent with changes in the temperature difference anomalies between ocean and air (Fig. 7). When the SCSSM is strong, the cold SST anomalies cover the whole of the tropical Indo-western Pacific regions, albeit with weaker-amplitude SST anomalies over the WNP (Fig. 7a, c); however, the temperature difference anomalies between ocean and air over the SMC (WNP) are positive (negative, Fig. 7b, d). This suggests the transportation of surface sensible heat from the ocean (atmosphere) to the atmosphere (ocean) over the SMC (WNP), which is not conducive to a decrease (increase) in atmospheric PPE over the SMC (WNP). The positive anomalies in surface latent heat flux that cover the entire Maritime Continent and extend slightly to the north, together with the insignificant negative anomalies in surface latent heat flux over the WNP (Fig. 6b). Those results suggest that both the surface sensible and latent heat fluxes are not conducive to a decrease (increase) in atmospheric PPE over the SMC (WNP).
Beside the surface sensible and latent heat fluxes, we also calculated the net shortwave and longwave radiation flux anomalies (Fig. 6c). Although the net shortwave and longwave radiation flux anomalies have opposite influences on atmospheric PPE over the WNP and SMC, the combined effects contribute to a decrease (increase) in atmospheric PPE over the SMC (WNP; Fig. 6c). Overall, the surface heat flux does not assist the decrease (increase) in atmospheric PPE over the SMC (WNP) except for the net shortwave radiation flux (Figs. 6d, 8a). Therefore, having demonstrated that the total surface heat fluxes are not favorable for a decrease (increase) in atmospheric PPE over the SMC (WNP) during strong SCSSM years (Fig. 8a), we must consider the other factors that control the PPE dipole pattern over the WNP and SMC.

In fact, the total latent heat release includes not only the surface latent heat release but also the latent heating released by condensation, which can be represented approximately the magnitude of the apparent heat source $\mathrm{Q}_{1}$ and heat sink $\mathrm{Q}_{2}$ (Yanai and Tomito 1998; Sobel and Bretherton 1998). The $Q_{1}$ and $\mathrm{Q}_{2}$ can be calculated from:

$$
\begin{aligned}
\left\langle Q_{1}\right\rangle & =c_{p}\left(\frac{p}{p_{0}}\right)^{\kappa}\left(\frac{\partial \theta}{\partial t}+\mathbf{V} \cdot \nabla \theta+\omega \frac{\partial \theta}{\partial p}\right) \\
& =c_{p}(\underbrace{\frac{\partial T}{\partial t}}_{\text {Local change }}+\underbrace{\mathbf{V} \cdot \nabla T}_{\text {Horizontal advection }}+\underbrace{\omega\left(\frac{p}{p_{0}}\right)^{\kappa} \frac{\partial \theta}{\partial p}}_{\text {Vertical transportation }}),
\end{aligned}
$$
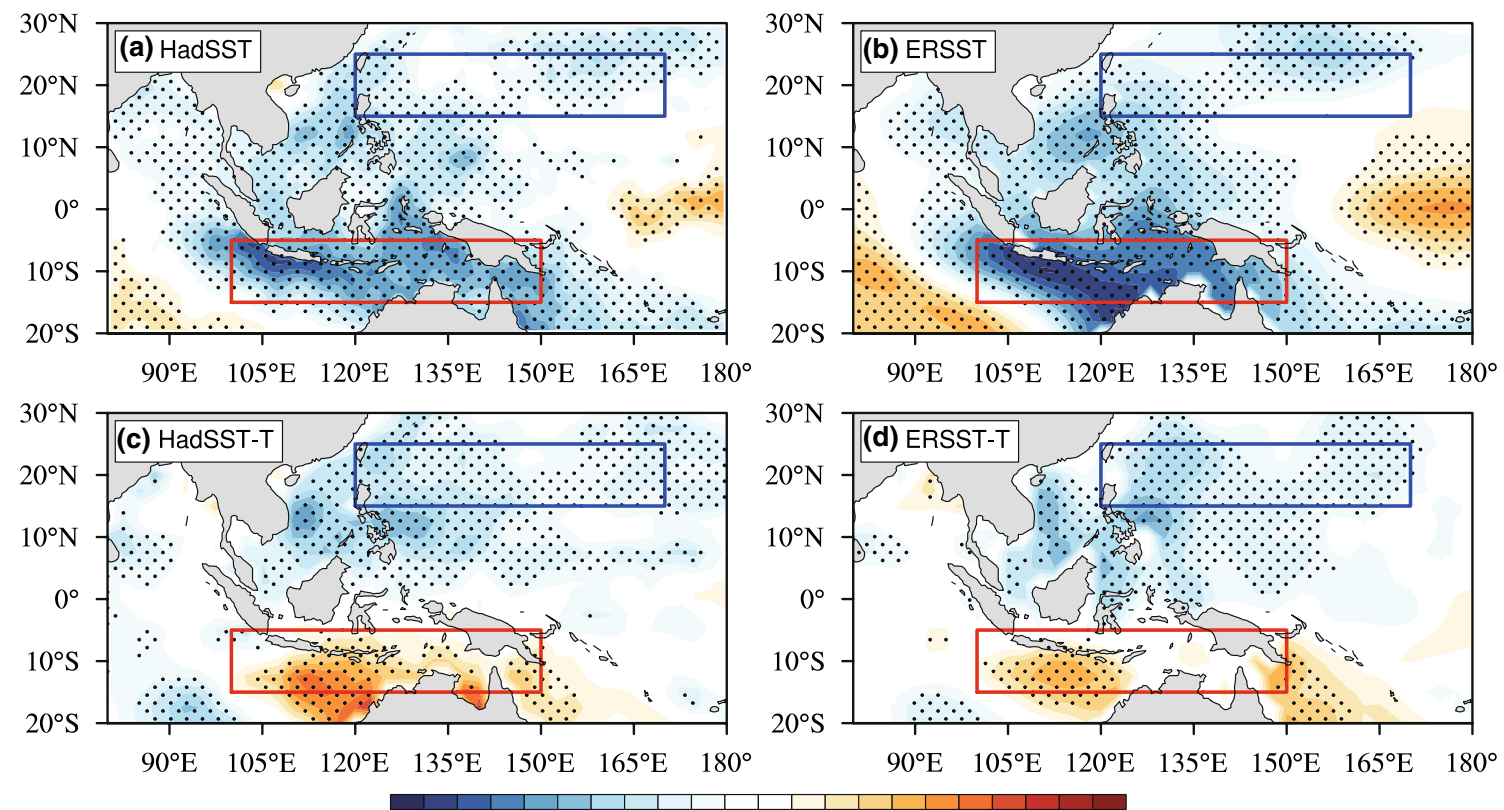

Fig. 7 Composite of the a HadISST anomalies (shading, ${ }^{\circ} \mathbf{C}$ ) and $\mathbf{c}$ the temperature difference between the HadISST and air (shading, ${ }^{\circ} \mathbf{C}$ ). $\mathbf{b}, \mathbf{d}$ As a, c but for ERSST dataset. The red (blue) rectangles same as in Fig. 1a. Black stipples in (a-d) indicate 95\% confidence level 


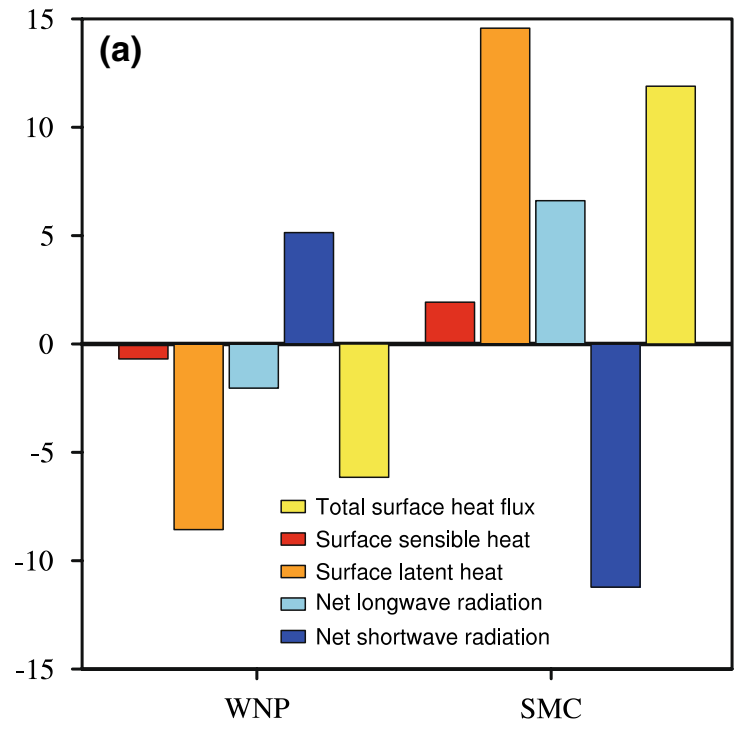

Fig. 8 a Composite of the surface sensible heat (red bar, $\mathrm{W} \mathrm{m}^{-2}$ ), surface latent heat (orange bar, $\mathrm{W} \mathrm{m}^{-2}$ ), net longwave (sky blue bar, $\mathrm{W} \mathrm{m}^{-2}$ ), net shortwave (blue bar, $\mathrm{W} \mathrm{m}^{-2}$ ), and total surface heat flux

$\left\langle Q_{2}\right\rangle=-L\left(\frac{\partial q}{\partial t}+\mathbf{V} \cdot \nabla q+\omega \frac{\partial q}{\partial p}\right)$

where

$\left\langle Q_{*}\right\rangle=\frac{1}{g} \int_{300}^{P_{00}} Q_{*} d p$

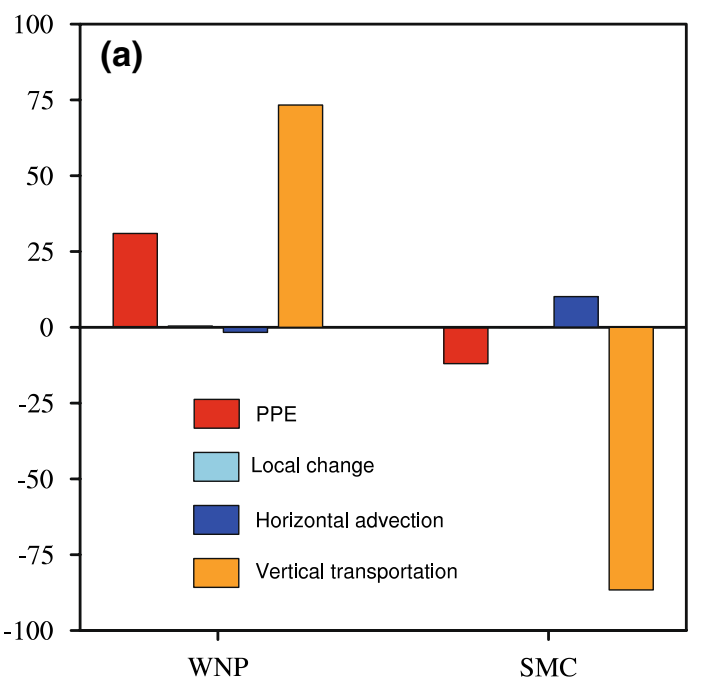

Fig. 9 a Composite of the JJA PPE (red bars, $10^{5} \mathrm{~J} \mathrm{~m}^{-2}$ ), the local change (sky blue bars, $\mathrm{W} \mathrm{m}^{-2}$ ), the horizontal advection (blue bars,

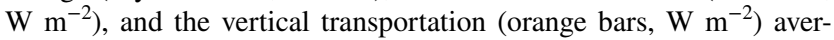
aged over the WNP and SMC; see $\mathbf{b}$ for locations. b Composite of

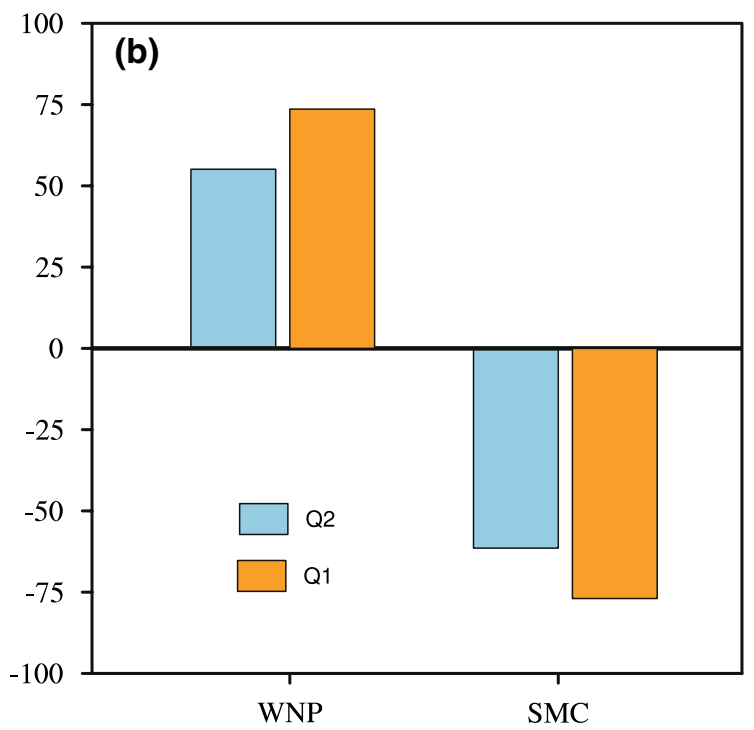

(yellow bar, $\mathrm{W} \mathrm{m}^{-2}$ ) over the WNP and SMC during JJA. b As a, but for the apparent heat source $\mathrm{Q}_{1}$ (sky blue bar, $\mathrm{W} \mathrm{m}^{-2}$ ), and heat sink $\mathrm{Q}_{2}$ (orange, $\mathrm{W} \mathrm{m}^{-2}$ )

where $L$ and $q$ are the latent heat of condensation and the specific humidity respectively; $\mathrm{V}$ and $\nabla$ indicate the horizontal velocity and the isobaric gradient operator. $\left\langle Q_{*}\right\rangle$ denotes the integration from the 300-hPa to surface.

The similar magnitude of $\mathrm{Q}_{1}$ and $\mathrm{Q}_{2}$ over the WNP and SMC indicate that the latent heat released by condensation is the major component of the heat source (Fig. 8b). Equation (7) demonstrates that the heat source $\mathrm{Q}_{1}$ includes the local change, the horizontal advection, and the vertical

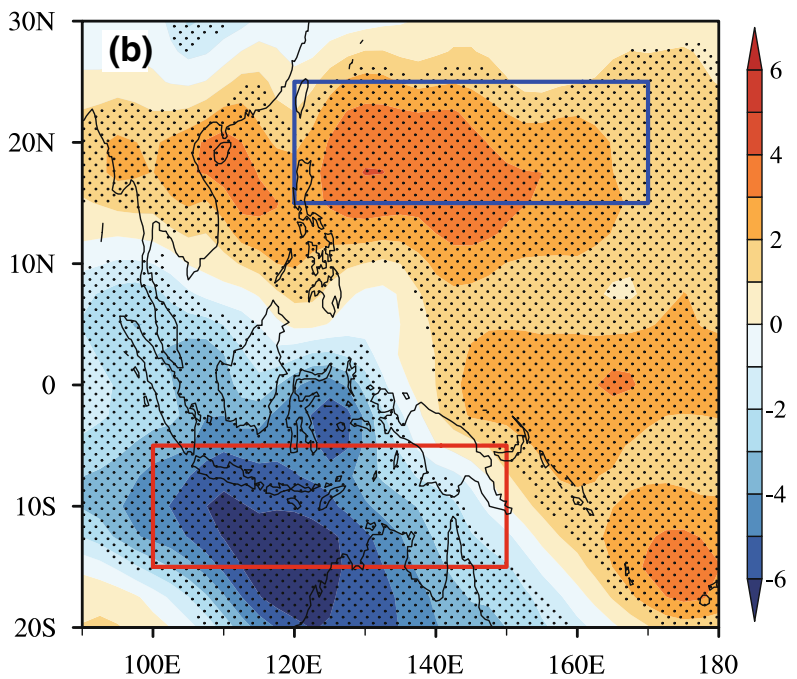

precipitable water content anomalies (shading, $\mathrm{kg} \mathrm{m}^{-2}$ ) during JJA. The red and blue rectangles are the same regions as in Fig. 1a. Black stipples in (b) indicate significance at the $95 \%$ confidence level 
transportation. In contrast to the horizontal advection and the local change associated with the temperature gradient, the intensity of the vertical transportation is much stronger (Fig. 9a), suggesting that the vertical transportation may play a dominant role in controlling variations in atmospheric PPE. Moreover, the intensity of latent heat released by condensation can also be measured by the precipitable water content (Huyan et al. 2017), which is shown in Fig. 9b. Both the location and pattern of precipitable water content are similar to those of atmospheric PPE (Figs. 3b, 9b), in accordance with the Fig. 6a. Actually, the PPE is strongly constrained by the large-scale meridional perturbation temperature gradient (Supporting Information Fig. S2), rather than the temperature gradient.

Due to the opposite effects between the latent heat released by condensation and the surface heat flux, this leads us to consider why the intensity of PPE over the WNP is stronger than that over the SMC. The intensity of latent heat released by condensation may be counteracted by greater surface heat flux (Figs. 8a, 9a), leading to the lower PPE over the SMC (Fig. 3a). Although the intensity of latent heat released by condensation is comparable weak over the WNP, the strong amplitude of atmospheric PPE may be caused by weakened counteracting effect of the lower surface heat flux on the latent heat released by condensation (Figs. 8a, 9a).
Hence, the intensity of PPE over the WNP is stronger as compared with those over the SMC.

As known, the latent heat released by condensation, controlling primarily PPE variation, is closely intimate with the precipitation. The precipitation and PPE over the WNP are both lagged the SCSSM, suggesting the influence of the SCSSM on the precipitation and PPE over there (Fig. 10a, b). The similar situation appears over the SMC (Fig. 10d, e). For the relationship between the precipitation and PPE over the WNP and SMC, there are distinctly different. The precipitation leading PPE by 2 weeks over the WNP indicates that the PPE may be induced by the precipitation (Fig. 10c); however, the reversed situation over the SMC illustrates that the precipitation delays to the PPE (Fig. 10f).

The above results can be interpreted as follows: when the SCSSM is strong, the increased moisture driven by enhanced southwesterly wind favors excess precipitation over the WNP (Fig. 11a), contributing to the increase in PPE through the latent released by condensation and corresponding negative $\mathrm{C}_{k}$ in this region. This indicates that the greater PPE is converted to PKE and induces the enhanced ascending motion over the WNP. Consequently, the descending motion reduces PPE and is corresponding to positive $\mathrm{C}_{k}$ over the $\mathrm{SMC}$, together with ascending motion over the WNP, suggesting the intensification of the anomalous SCSSM Hadley circulation. The lower-level southeasterly (a) SCSSM \& $\mathrm{P}_{\mathrm{WNP}}$

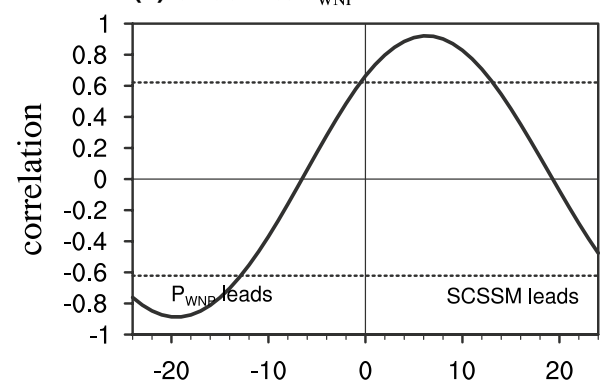

(d) SCSSM \& $\mathrm{P}_{\mathrm{SMC}}$

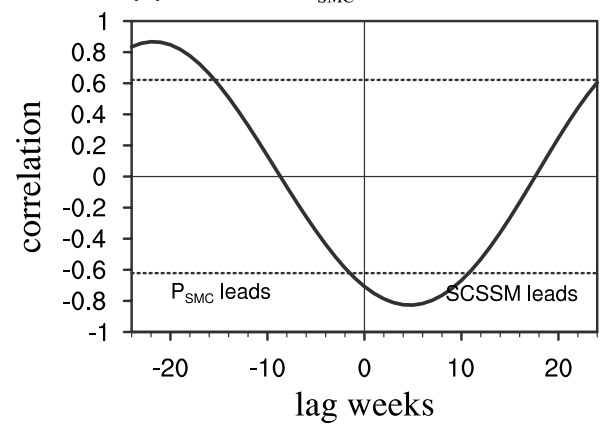

(b) SCSSM \& PPE

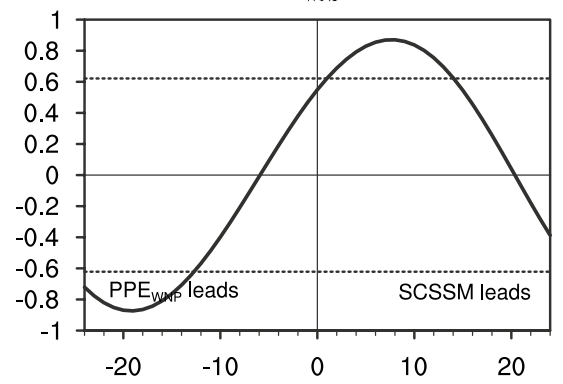

(e) SCSSM \& PPE $\mathrm{SMC}$

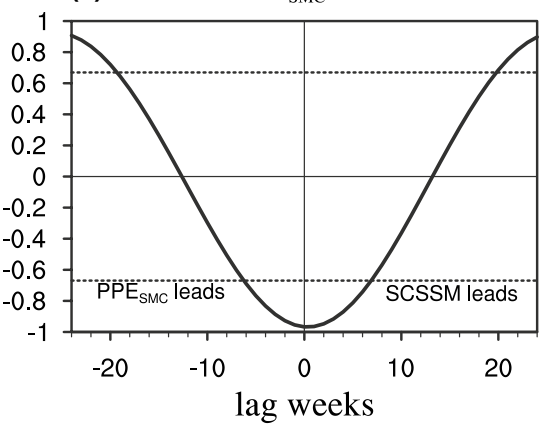

(c) $\mathrm{PPE}_{\mathrm{WNP}} \& \mathrm{P}_{\mathrm{WNP}}$

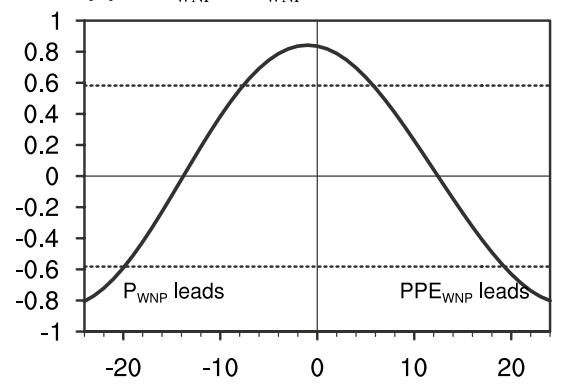

(f) $\mathrm{PPE}_{\mathrm{SMC}} \& \mathrm{P}_{\mathrm{SMC}}$

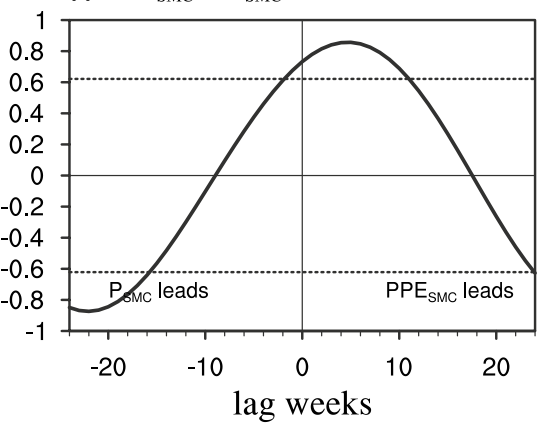

Fig. 10 Lead-lag correlations between two different indices by using weekly mean data. a The SCSSM index and precipitation index over the WNP $\left(\mathrm{P}_{\mathrm{WNP}}\right)$; $\mathbf{b}$ The SCSSM index and PPE index over the WNP $\left(\mathrm{PPE}_{\mathrm{WNP}}\right)$; $\mathbf{c}$ The $\mathrm{P}_{\mathrm{WNP}}$ and $\mathrm{PPE}_{\mathrm{WNP}}$ d-f As a-c, but for over the
SMC. The weekly mean data are derived from the daily mean and have been smoothed with a 9-week running to suppress the transient disturbance. The dashed line indicates the $99 \%$ confidence level 


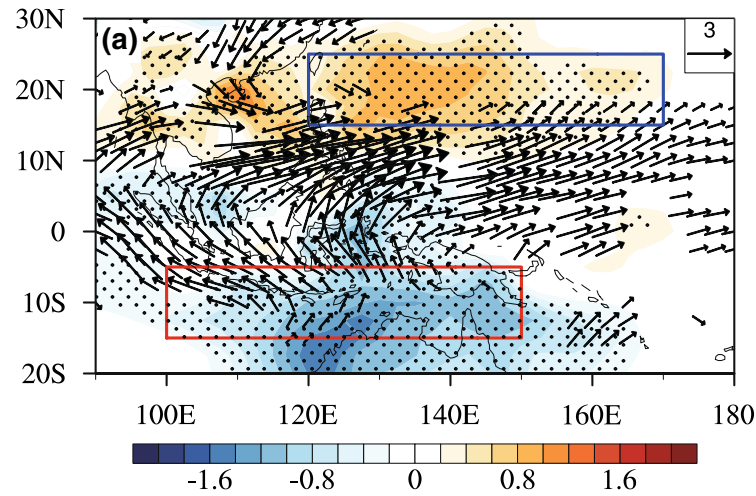

Fig. 11 a Composite of the specific humidity (shading, $\mathrm{g} \mathrm{kg}^{-1}$ ) and the wind field at $925-\mathrm{hPa}$ (vectors, $\mathrm{m} \mathrm{s}^{-2}$ ) during JJA. b The JJAmean wind climatology at $925-\mathrm{hPa}$. Black stipples in (a) indicate sig-

Table 2 The partial correlation coefficients between the SCSSM index and IOD index during JJA for period 1948-2015

\begin{tabular}{|c|c|c|c|c|}
\hline & \multirow[t]{2}{*}{ Correlations } & \multicolumn{3}{|c|}{ Partial correlations } \\
\hline & & $\begin{array}{l}\text { Rm-precipi- } \\
\text { tation dipole }\end{array}$ & $\begin{array}{l}\text { Rm-PPE } \\
\text { dipole }\end{array}$ & $\begin{array}{l}\text { Rm-lower- } \\
\text { level PPE } \\
\text { dipole }\end{array}$ \\
\hline $\begin{array}{l}\text { (IOD index, } \\
\text { SCSSM } \\
\text { index) }\end{array}$ & $0.46^{*}$ & 0.23 & $0.33^{*}$ & 0.26 \\
\hline
\end{tabular}

Rm-precipitation dipole (PPE dipole and lower-level PPE dipole) indicates the removal of the JJA precipitation (PPE dipole and lowerlevel PPE dipole) signals. The asterisk indicates $99 \%$ confidence level

wind induced by the anomalous SCSSM Hadley circulation is strengthened off Sumatra and Java coasts, and then shift to be the southwesterly wind after crossing the equator (Fig. 11a). The enhanced southwesterly wind is superimposed on the JJA-mean southwesterly wind (Fig. 11b), indicating the enhancement of the SCSSM. The enhanced SCSSM further promotes the development of the SCSSM Hadley circulation and precipitation dipole, implying that the SCSSM can maintain development through the positive convection-PPE-circulation feedback.

\section{Discussions}

Previous studies reported that ENSO has significant influence on the interannual variation of the SCSSM (Wang et al. 2009; He and Wu 2014), while correlation coefficient (0.36) between the SCSSM and ENSO during JJA is relative small. In addition, ENSO is not significantly correlated with the PPE dipole with the value of -0.06 . Those results may imply the weak interaction between ENSO and SCSSM through the PPE dipole during JJA.

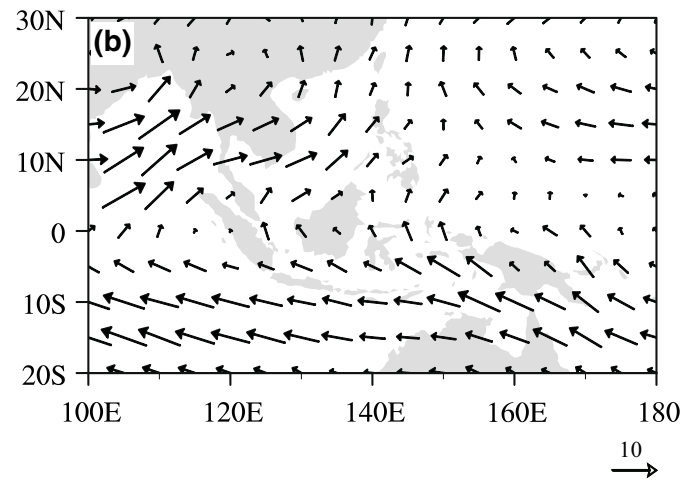

nificance at the $99 \%$ confidence level, and only wind vectors in (a) that are significant at the $95 \%$ confidence level are plotted

Compared with the weak SCSSM-ENSO interaction, the SCSSM can affect the IOD through the precipitation dipole over the WNP and SMC during JJA (Zhang et al. 2018). Similar to the precipitation dipole, the IOD index are both significantly correlated with the SCSSM and PPE dipole index in JJA (Table 2). It is reasonable to assume that the PPE dipole may play a crucial role in connecting the SCSSM and IOD in JJA, which can be illustrated by the partial correlations analysis (Table 2). When removing the PPE dipole signals, the correlation between the SCSSM and IOD is decreased from 0.46 to 0.33 (Table 2). Though it is significant, the explained variance is reduced by about half. This implies that PPE dipole may play an important role in the relationship between the SCSSM and IOD.

In addition, Wang et al. (2018b) found that the lowerlevel PPE $(1000-850 \mathrm{hPa})$ is the dominant layer of the PPE in the whole troposphere during the IOD events, albeit with the weak counteracting effect from the upper-level PPE over the east pole of the IOD. However, this may weaken the influence of the whole troposphere PPE dipole on the east pole of the IOD. The lower-level PPE dipole index, thus, is defined as PPE dipole index but for the lower-level troposphere $(1000-850 \mathrm{hPa})$. When the lower-level PPE signals are excluded, the correlation between the SCSSM and IOD becomes insignificant (Table 2), demonstrating the potential linkage between the SCSSM and the IOD from the viewpoint of the PPE, especially for the lower-level PPE. These results are consistent with the study of Zhang et al. (2018), who indicated that the SCSSM affecting the IOD through enhancing lower-level southeasterly wind anomalies off Sumatra-Java coasts is strongly constrained in the lower-level troposphere. Uncovering the important role of the PPE in connecting the SCSSM and IOD further improves and deepens the understanding of the dynamic insight of the SCSSM affecting the IOD from the perspective of the regional energetics. 
Fig. 12 Schematic diagram of the positive convection-PPEcirculation feedback during the strong SCSSM years, and vice versa

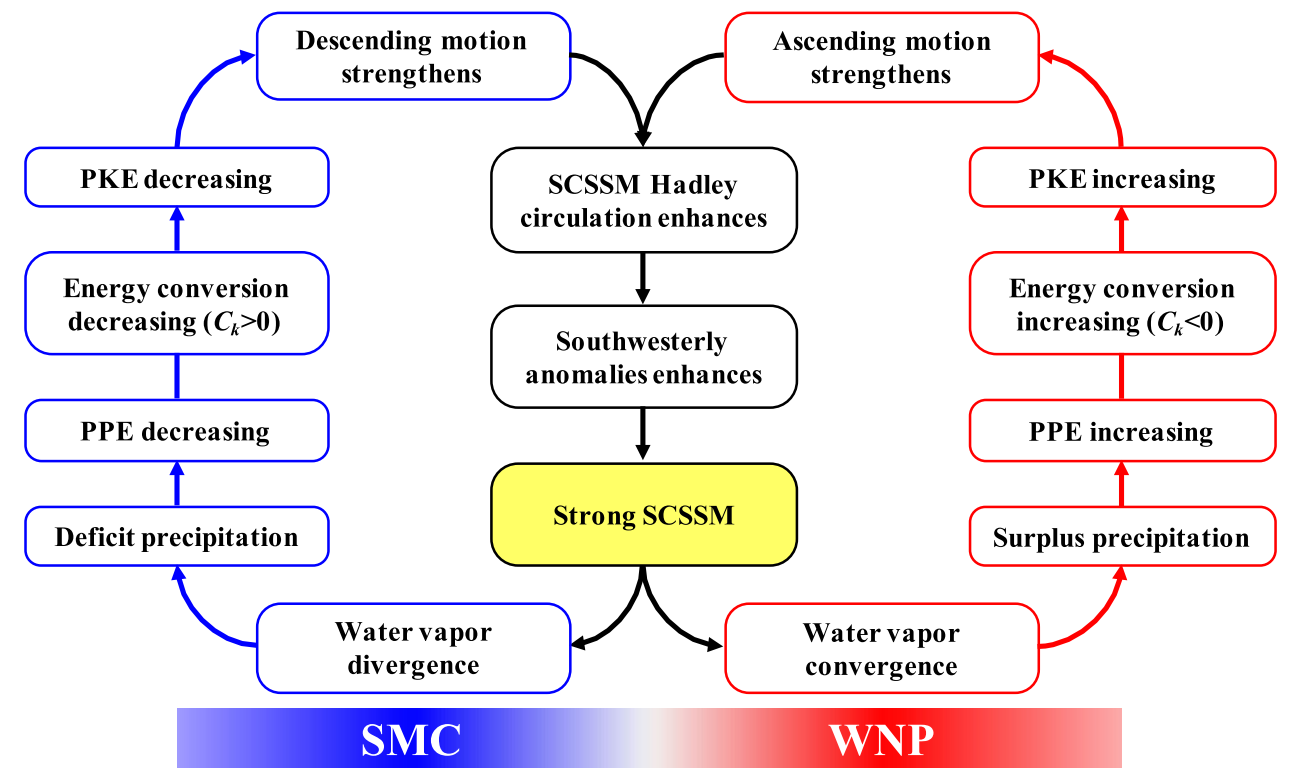

\section{Summary}

The PPE theory provides a new perspective to view Asian summer monsoon research; i.e., regional energetics (Wang et al. 2012; Huyan et al. 2017). Although changes in atmospheric circulation related to the SCSSM have been investigated ( $\mathrm{Li}$ and Zeng 2002; Wang et al. 2009; Zhang et al. 2018), less attention has been paid to the atmospheric energy variations associated with the SCSSM on the interannual variability. Thus, in this study we investigated the processes of atmospheric energy variation and their relation to the convection (circulation) associated with the SCSSM based on the PPE theory. For strong SCSSM years, the enhanced southwesterly wind bringing more moisture to the WNP favors the surplus precipitation over there in JJA, inducing the greater PPE and corresponding to negative $\mathrm{C}_{k}$ in suit. This indicates that more PPE is converted to PKE, which further enhances ascending motion in this region. Consequently, the lower PPE induced by the descending motion is accompanied with positive $\mathrm{C}_{k}$ over the SMC, suggesting less PPE is transformed into PKE and in turn favoring the intensification of the descending motion and deficit precipitation in suit. The ascending motion over the WNP, together with the descending motion over the SMC, illustrate the intensification of the anomalous SCSSM Hadley circulation. The enhanced lowerlevel southeasterly wind off Sumatra and Java, induced by the anomalous SCSSM Hadley circulation, turns into the southwesterly wind after crossing the equator. Superimposed on the JJA-mean southwesterly wind, the enhanced southwesterly wind contributes to the intensification of SCSSM. Therefore, the SCSSM can maintain development through the positive convection-PPE-circulation feedback during JJA, which can be clearly illustrated by the schematic diagram in Fig. 12.

In contrast to the surface heat flux, the latent heat released by condensation is the dominant control on variations in PPE. Furthermore, due to the weakened counteracting effect of the lower surface heat flux on the latent heat released by condensation process, the amplitude of atmospheric PPE is stronger over the WNP than those over the SMC. Based on the widespread application of the PPE in the monsoon research, it is expected that the energy conversion processes of other monsoon systems in earth, e.g., South Asian summer monsoon, will be studied from the viewpoint of the PPE in the future. In addition, the atmospheric PPE dipole plays an important role in bridging between the SCSSM and the IOD, and this improves the understanding of the dynamic processes of the SCSSM affecting the IOD from the point view of the regional energetics.

Acknowledgements This work was jointly sponsored by the National Natural Science Foundation of China (NSFC) Project (41530424, 41790474) and SOA International Cooperation Program on Global Change and Air-Sea Interactions (GASI-IPOVAI-03).

Open Access This article is distributed under the terms of the Creative Commons Attribution 4.0 International License (http://creativeco mmons.org/licenses/by/4.0/), which permits unrestricted use, distribution, and reproduction in any medium, provided you give appropriate credit to the original author(s) and the source, provide a link to the Creative Commons license, and indicate if changes were made. 


\section{References}

Bretherton CS, Widmann M, Dymnidov VP, Wallace JM, Blade I (1999) The effective number of spatial degrees of freedom of a time-varying field. J Climate 12:1990-2009

Dee DP et al (2011) The ERA-interim reanalysis: configuration and performance of the data assimilation system. Q J R Meteorol Soc 137:553-597. https://doi.org/10.1002/qj.828

Dong D, Li JP, Huyan LD, Xue JQ (2017) Atmospheric energetics over the tropical Pacific during the ENSO cycle. J Climate 30(10):3635-3654

Edmon HJ Jr (1978) A reexamination of limited-area available potential energy budget equations. J Atmos Sci 35(9):1655-1659

Gao L, Li JP (2007) Progress in the study of atmospheric energy efficiency. Adv Earth Sci 22:486-494 (in Chinese)

Gao L, Li JP (2012) Relationship and mechanism between perturbation potential energy and atmospheric general circulation anomalies. Chin J Geophys 55:359-374

Gao L, Li JP (2013) Impacts and mechanism of diabatic heating on atmospheric perturbation potential energy. Chin J Geophys 56:3255-3269

Gao L, Li JP, Ren HL (2006) Some characteristics of the atmosphere during an adiabatic process. Prog Nat Sci 16(6):644-648

He ZQ, Wu RG (2014) Indo-Pacific remote forcing in summer rainfall variability over the South China Sea. Climate Dyn 42:2323-2337. https://doi.org/10.1007/s00382-014-2123-7

He ZQ, Wu RG, Wang W (2016) Signals of the South China Sea summer rainfall variability in the Indian Ocean. Climate Dyn 46:3181-3195. https://doi.org/10.1007/s00382-015-2760-5

Huang BY, Thorne PW, Banzon VF, Boyer T, Chepurin G, Lawrimore JH, Menne MJ, Smith TM, Vose RS, Zhang HM (2017) Extended reconstructed sea surface temperature, version 5 (ERSSTv5): upgrades, validations, and intercomparisons. J Climate 30:8179-8205

Huyan LD, Li JP, Zhao S, Sun C, Dong D, Liu T, Zhao YF (2017) The impact of layer perturbation potential energy on the East Asian summer monsoon. J Climate 30(17):7087-7103

Johnson DR (1970) The available potential energy of storms. J Atmos Sci 27(5):727-741

Kalnay E, Kanamitsu M, Kistler R, Collins W, Deaven D, Gandin L, Iredell M, Saha S, White G, Woollen J (1996) The NCEP/NCAR 40-year reanalysis project. Bull Am Meteor Soc 77(3):437-471. https://doi.org/10.1175/1520-0477(1996)077\%3c0437:TNYRP $\% 3 \mathrm{e} 2.0 . \mathrm{CO} ; 2$

Kanamitsu M, Ebisuzaki W, Woollen J, Yang S, Hnilo J, Fiorino M, Potter G (2002) NCEP-DOE AMIP-II reanalysis (R-2). Bull Am Meteor Soc 83:1631-1643. https://doi.org/10.1175/ BAMS-83-11-1631

Kim YH, Kim MK (2013) Examination of the global Lorenz energy cycle using MERRA and NCEP-reanalysis 2. Climate Dyn 40(5):1499-1513

Li JP, Gao L (2006) Theory on perturbation potential energy and its applications-concept, expression and spatio-temporal structures of perturbation potential energy. Chin J Atmos Sci 30(5):834

Li JP, Zeng QC (2002) A unified monsoon index. Geophys Res Lett 29(8):115. https://doi.org/10.1029/2001GL013874

Li JP, Zeng QC (2003) A new monsoon index and the geographical distribution of the global monsoons. Adv Atmos Sci 20(2):299-302

Li LM, Ingersoll AP, Jiang X, Feldman D, Yung YL (2007) Lorenz energy cycle of the global atmosphere based on reanalysis datasets. Geophys Res Lett. https://doi.org/10.1029/2007GL029985

Li JP, Wu ZW, Jiang ZH, He JH (2010) Can global warming strengthen the East Asian summer monsoon? J Climate 23(24):6696-6705

Li LM, Jiang X, Chahine MT, Wang J, Yung YL (2011) The mechanical energies of the global atmosphere in El Niño and La Niña years. J Atmos Sci 68(12):3072-3078. https://doi.org/10.1175/ JAS-D-11-072.1

Li JP, Sun C, Jin FF (2013) NAO implicated as a predictor of Northern Hemisphere mean temperature multidecadal variability. Geophys Res Lett 40(20):5497-5502

Liu T, Li JP, Li YJ, Zhao S, Zheng F, Zheng JY, Yao ZX (2017) Influence of the May Southern annular mode on the South China Sea summer monsoon. Climate Dyn. https://doi.org/10.1007/s0038 2-017-3753-3

Lorenz EN (1955) Available potential energy and the maintenance of the general circulation. Tellus 7:157-167. https://doi.org/10.3402/ tellusa.v7i2.8796

Margules M (1910) Uber die energie der stiirme (On the energy of storms). Zentralanstalt Meteor Geodyn 51:533-595

Oort AH (1964) On estimates of the atmospheric energy cycle. Mon Weather Rev 92(4):483-499. https://doi.org/10.1175/15200493(1964)092,0483:OEOTAE.2.3.CO;2

Oort AH (1971) The observed annual cycle in the meridional transport of atmospheric energy. J Atmos Sci 28:325-339

Oort AH, Ascher SC, Levitus S, Peixóto JP (1989) New estimates of the available potential energy in the world ocean. J Geophys Res 94:3187-3200

Pan Y, Li LM, Jiang X, Li G, Zhang W, Wang X, Ingersoll AP (2017) Earth's changing global atmospheric energy cycle in response to climate change. Nat Commun 8:14367

Peixóto JP, Oort AH (1974) The annual distribution of atmospheric energy on a planetary scale. J Geophys Res 79(15):2149-2159

Pyper BJ, Peterman RM (1998) Comparison of methods to account for autocorrelation in correlation analyses of fish data. Can J Fish Aquat Sci 55(9):2127-2140

Rayner N, Parker DE, Horton E, Folland C, Alexander L, Rowell D, Kent E, Kaplan A (2003) Global analyses of sea surface temperature, sea ice, and night marine air temperature since the late nineteenth century. J Atmos Sci. https://doi.org/10.1029/2002J D002670

Roullet G, Capet X, Maze G (2014) Global interior eddy available potential energy diagnosed from Argo floats. Geophys Res Lett 41(5):1651-1656

Smith PJ (1969) On the contribution of a limited region to the global energy budget. Tellus 21(2):202-207. https://doi. org/10.1111/j.2153-3490.1969.tb00432.x

Smith PJ, Vincent DG, Edmon HJ Jr (1977) The time dependence of reference pressure in limited region available potential energy budget equations. Tellus 29(5):476-480

Sobel AH, Bretherton CS (1998) modeling tropical precipitation in a single column. J Climate 13(24):4378-4392

Wang B, Huang F, Wu Z, Yang J, Fu X, Kikuchi K (2009) Multi-scale climate variability of the South China Sea monsoon: a review. Dyn Atmos Oceans 47(1):15-37. https://doi.org/10.1016/j.dynat moce.2008.09.004

Wang L, Li JP, Guo Y (2012) Governing equations of atmospheric layer perturbation potential energy and its applications-energy budget of the South China Sea summer monsoon activity. Chin J Atmos Sci 36(4):769-783

Wang L, Li JP, Wang ZG, Li YJ, Zheng F (2015) The oscillation of the perturbation potential energy between the extratropics and tropics in boreal winter. Atmos Sci Lett 16:119-126. https://doi. org/10.1002/asl2.532

Wang QY, Li JP, Li YJ, Xue JQ, Zhao S, Xu YD, Wang YH, Zhang YZ, Dong D, Zhang JW (2018a) Modulation of tropical cyclone tracks over the western North Pacific by intra-seasonal Indowestern Pacific convection oscillation during the boreal extended summer. Climate Dyn 52:913-927. https://doi.org/10.1007/s0038 2-018-4264-6

Wang YH, Li JP, Zhang YZ, Wang QY, Qin JH (2018b) Atmospheric energetics over the tropical Indian Ocean during Indian Ocean 
dipole events. Climate Dyn. https://doi.org/10.1007/s0038 2-018-4510-y

Wu RG, Kirtman BP, Pegion K (2006) Local air-sea relationship in observations and model simulations. J Climate 19(19):4914-4932

Wu RG, Wen ZP, Yang S, Li YQ (2010) An interdecadal change in southern China summer rainfall around 1992/93. J Climate 23(9):2389-2403. https://doi.org/10.1175/2009JCLI3336.1

Xie SP, Hu K, Hafner J, Tokinaga H, Du Y, Huang G, Sampe T (2009) Indian Ocean capacitor effect on Indo-western Pacific climate during the summer following El Niño. J Climate 22(3):730-747. https://doi.org/10.1175/2008JCLI2544.1

Yanai M, Tomito T (1998) Seasonal and interannual variability of atmospheric heat sources and moisture sinks as determined from NCEP-NCAR reanalysis. J Climate 11(3):463-482
Zhang YZ, Li JP, Xue JQ, Feng J, Wang QY, Xu YD, Wang YH, Zheng F (2018) Impact of the South China Sea summer monsoon on the Indian Ocean dipole. J Climate 31(16):6557-6573. https://doi. org/10.1175/JCLI-D-17-0815.1

Publisher's Note Springer Nature remains neutral with regard to jurisdictional claims in published maps and institutional affiliations. 